\title{
The Role of Ethylene in Water-deficit Stress Responses in Betula \\ papyrifera Marsh
}

\author{
Mengmeng $\mathbf{G u}^{1,4}$ \\ Department of Horticulture, University of Arkansas, Fayetteville, AR 72701
}

\author{
James A. Robbins ${ }^{3}$ \\ Cooperative Extension Service, University of Arkansas, P.O. Box 391, \\ Little Rock, AR 72203
}

Curt R. Rom ${ }^{2}$

Department of Horticulture, University of Arkansas, Fayetteville, AR 72701

Additional index words. paper birch, gas exchange, chlorophyll fluorescence, 1-methylcyclopropene, silver thiosulfate

\begin{abstract}
One-year-old paper birch (Betula papyrifera Marsh.) seedlings were exposed to water deficit, ethylene, or inhibitors of ethylene action under greenhouse conditions to investigate ethylene's role in water-deficit stress-induced leaf abscission. Exposing wellwatered and water-stressed paper birch to $20 \mathrm{ppm}$ ethylene resulted in more than $50 \%$ leaf abscission after $96 \mathrm{~h}$ regardless of plant water status. However, application of a physiological level $(1 \mathrm{ppm})$ of ethylene did not cause leaf abscission in either well-watered or water-stressed paper birch. Inhibitors of ethylene action (1ppm 1-methylcyclopropene or $0.1 \mathrm{~mm}$ silver thiosulfate) did not affect predawn water potential, gas exchange, or chlorophyll fluorescence. A significant increase in ethylene production was not detected in water-stressed paper birch before the onset of significant leaf abscission. Based on these observations, ethylene would appear to play a minor role in water-deficit stressinduced leaf abscission in paper birch.
\end{abstract}

Paper birch (Betula papyrifera Marsh.) is commonly used as a landscape tree for its attractive white bark. It is native in northern North America (USDA, 2005) with a southern-most natural distribution in higher elevations between Tennessee and North Carolina. Paper birch grows best where provided with ample moisture and is adapted to a variety of soils (Farrar, 1995). Water deficit is a severe environmental stress to paper birch in the landscape and nursery production. Water-deficit stress reduced net photosynthesis both under field and greenhouse conditions ( $\mathrm{Gu}$ et al., 2003, 2004) and was generally considered as a serious limitation to plant growth (Cinnirella et al., 2002; Ladjal et al., 2000).

In response to water-deficit stress, plants may adapt by developing smaller leaves or abscising leaves to reduce water loss (Cinnirella, et al., 2002; Fort et al., 1998; Wullschleger and Oosterhuis, 1991). The desert plant palo verde (Parkinsonia L.) abscises all

\footnotetext{
Received for publication 16 Nov. 2006. Accepted for publication $18 \mathrm{Apr} .2007$.

${ }^{1}$ Graduate assistant. Current status: Assistant Professor, Mississippi State University, Department of Plant and Soil Sciences, Box 9555, Mississippi State, MS 39762.

${ }^{2}$ Professor.

${ }^{3}$ Professor-Extension Specialist.

${ }^{4}$ To whom reprint requests should be addressed; e-mailmgu@pss.msstate.edu.
}

leaves during drought and only branches remain (Connor et al., 2005). Ziziphus rotundifolia Lam. was found to shed lower and inner leaves followed by general leaf abscission in response to severe water deficit (Arndt et al., 2001). Miniature rose (Rosa hybrida L. cv Bluessette) showed extensive leaf abscission after water-deficit stress (Morgan et al., 1990). Defoliation might be a mechanism to remobilize and redistribute assimilates for coping with water deficit, which supplies limited assimilate for newer and upper leaves when dealing with severe water-deficit stress (Yin et al., 2005). When exposed to 5-week water deficit, B. papyrifera had more significant leaf abscission than the other birch genotypes and maintained high leaf gas exchange rates (unpublished data).

Ethylene biosynthesis may be stimulated under various environmental stresses, including water-deficit stress (Morgan and Drew, 1997). An increase in ethylene production during water-deficit stress may play a role in a plant's acclimation to water-deficit stress. Ethylene was responsible for leaf abscission of water-stressed mandarin after being rewatered (Gomez-Cadena et al., 1996). The effects of ethylene, transitory or long term, vary considerably among species (Hall and Smith, 1995). Although examples of abscission of leaves in response to water-deficit stress are compelling, causality is unproven. A role of ethylene in water-deficit stress responses in paper birch remains unknown.
Exogenous application of ethylene or the ethylene precursor (1-aminocyclopropane-1carboxylate) can accelerate leaf abscission, whereas inhibitors of ethylene synthesis and action (e.g., aminoethoxyvinylglycine and $\mathrm{Ag}^{+}$) retard leaf senescence (Taiz and Zeiger, 1998). Silver thiosulfate (STS) has been used to inhibit ethylene action to prolong vase life of cut flowers (Cameron and Reid, 1981). 1-methylcyclopropene (1-MCP), a recently identified gaseous inhibitor of ethylene action, binds to ethylene receptors (Sisler and Serek, 1997) and has been shown to specifically but transiently suppress ethylene responses, including delaying ripening in banana and apple (Fan and Mattheis, 1999; Jiang et al., 1999), changing the aroma profile in apricot (Botondi et al., 2003), reducing ethylene-induced flower petal abscission (Cameron and Reid, 2001), and abscission of bud, flower, and leaf in Geraldton waxflower, Chamelaucium uncinatum Schauer (Serek et al., 1995), and improving shelf life of miniature roses (Muller et al., 2000; Serek et al., 1994).

The objective of this study was to explore the role of ethylene in water-deficit stress responses in paper birch. Previous research indicated paper birch had more leaf abscission than the other three birch genotypes and maintained high gas exchange levels when exposed to water deficits (unpublished data). The hypothesis in this study was that ethylene plays a role in inducing leaf abscission in paper birch exposed to water deficit.

\section{Materials and Methods}

One-year-old paper birch seedlings were obtained from Lawyer Nursery (Plains, MT) planted in 4-1 pots with Sun Gro SB500 (Sun Gro Horticulture, Bellevue, WA) on 20 June 2005 and grown in a greenhouse. Ten grams of Osmocote $14 \mathrm{~N}-4 \mathrm{P}-11 \mathrm{~K}$ (Scotts, Marysville, $\mathrm{OH}$ ) were top-dress applied to each pot at planting. Plants were trained to a single shoot. Plants were watered daily to container capacity until studies were started on 12 July 2005.

Expt. 1: Effect of 20-ppm ethylene and water deficit on leaf abscission of $\mathrm{B}$. papyrifera. Water-deficit treatment was similar to "target water potential" described by Cregg (2004). The relation between the plant and container weight $(W)$ and predawn water potential $\left(\psi_{\text {predawn }}\right)$ was determined during a dry-down cycle in a preliminary experiment. Each value of $W$ is associated with a certain level of $\psi_{\text {predawn }}$.

In this study, $40 \%$ of the original $W$ was chosen to induce water-deficit conditions (target water potential; $\psi_{\text {predawn }} \approx-1.75$ $\mathrm{MPa}$ ) in the plants. The combined weight of the container and plant was taken daily at 1900 HR (CDST). For the water-deficit treatments, plants were watered to runoff and allowed to dry until the $W$ deceased below $40 \%$ of its original value. A requisite volume of water was applied to each container to reach $40 \%$ of its original weight daily. 
Well-watered plants were watered daily to container capacity.

After the combined weight of container and water-stressed plants reached $40 \%$ of their original value, predawn water potential $\left(\psi_{\text {predawn }}\right)$ was measured at $600 \mathrm{HR}$ with PST 55-15 thermocouple psychrometers connected to a Wescor HR-33T microvoltmeter (Wescor, Logan, UT) as described by Oosterhuis and Wulleschleger (1987). One leaf disc was punched from the center of half of the leaf on each tree and enclosed in psychrometer chambers, which was emerged in a $25{ }^{\circ} \mathrm{C}$ water bath for $4 \mathrm{~h}$ before readings were taken.

Both well-watered and water-stressed plants were transported to the laboratory for ethylene treatment. Two groups of two wellwatered plants and two water-stressed plants were put into two 69-L clear plastic boxes. The box had one septum inserted at the top. The lid of the box was sealed using laboratory tape (VWR International, West Chester, PA). Ethylene was injected into the box to reach a final concentration of $20 \mathrm{ppm}(\mathrm{v} / \mathrm{v})$. Ethylene concentration was verified from a $2-\mathrm{mL}$ sample extracted and measured using a Hewlett-Packard 6890 gas chromatograph (GC) (Wilmington, DE) equipped with a HayeSep T column $\left(6^{\prime} \times 1 / 8^{\prime \prime} \times 0.085^{\prime \prime}, 80 / 100, \mathrm{~S} / \mathrm{N}\right.$ 98-20906; Alltech Associates, Inc., Deerfield, IL). Detection was by flame ionization detector. The oven temperature was set as $60{ }^{\circ} \mathrm{C}$. Helium was used as carrier gas with a flow rate of $30 \mathrm{~mL} / \mathrm{min}$. Another two groups of well-watered plants and water-stressed plants were put in two additional boxes with no exogenous ethylene as a control.

After $96 \mathrm{~h}$, boxes were opened and the number of abscised leaves and retained leaves was counted for each tree. Leaf abscission was expressed as a percentage of total leaves.

Expt. 2: Effect of water deficit and ethylene inhibitors on B. papyrifera. Twenty-four paper birch plants of similar size were selected and four plants were randomly assigned to one of the following six treatments: 1) well-watered control (CC); 2) water-stressed (CS); 3) 1-MCP + wellwatered (MC); 4) 1-MCP + water-stressed (MS); 5) STS + well-watered (TC); and 6) STS + water-stressed (TS). Water-deficit treatment was the same as described in Expt. 1. Plants were treated with $1 \mathrm{ppm} 1-\mathrm{MCP}$ (SmartFresh; AgroFresh, Philadelphia, PA) for $4 \mathrm{~h}$ in box as described in Expt. 1. The yield of 1-MCP from SmartFresh powder was checked following the method of R. Beaudry (personal communication).

STS solution was prepared and applied following the method of Cameron and Reid (1981). Stock solutions of $0.1 \mathrm{M}$ sodium thiosulfate and $0.1 \mathrm{M}$ silver nitrate were mixed with a molar ratio between silver and thiosulfate of 1:4 immediately before STS treatment. STS solution $(0.1 \mathrm{~mm})$ was sprayed on leaves until runoff.

Gas exchange, $\psi_{\text {predawn}}$, chlorophyll fluorescence, and ethylene production measurements were taken at $1,2,6,9,13,26$, and $35 \mathrm{~d}(\mathrm{~s})$ after treatment (DAT).
The fifth most recently expanded leaf was tagged on each tree at the beginning of the experiment. Leaf gas exchange was measured from $900 \mathrm{HR}$ to $1300 \mathrm{HR}$ (CDST) with a CIRAS-1 (PP Systems, Haverhill, MA) infrared gas analyzer with the Parkinson's leaf cuvette. Gas exchange measurements were taken on a $2.5-\mathrm{cm}^{2}$ section on the center of half of the tagged leaf on all dates to minimize variability resulting from leaf age and position. The microprocessor was set to maintain cuvette conditions of $360 \mathrm{ppm} \mathrm{CO}_{2}, 25^{\circ} \mathrm{C}$, $50 \%$ relative humidity, and $1300 \mu \mathrm{mol} \cdot \mathrm{m}^{-2} \cdot \mathrm{s}^{-1}$ photosynthetically active radiation.

Chlorophyll fluorescence was measured on the same tagged leaf with a pulse-modulated fluorometer FMS2 (Hansatech Instruments Ltd., Norfolk, UK) at noon following the method of Cheng (2003). Maximum and minimum fluorescence $\left(F_{\mathrm{m}}\right.$ and $\left.F_{\mathrm{o}}\right)$ were measured after the leaf was dark-adapted for $15 \mathrm{~min}$ to close all PSII reaction centers. Maximum and minimum light-adapted fluorescence $\left(F_{\mathrm{m}}{ }^{\prime}\right.$ and $\left.F_{\mathrm{o}}{ }^{\prime}\right)$ and steady-state fluorescence $\left(\mathrm{F}_{\mathrm{s}}\right)$ were taken at $1300 \mathrm{HR}$ (CDST). The maximum PSII efficiency of dark-adapted leaves was calculated as: $F_{\mathrm{v}} / F_{\mathrm{m}}=\left(F_{\mathrm{m}}-F_{\mathrm{o}}\right) / F_{\mathrm{m}}$ (van Kooten and Snel, 1990). The efficiency of excitation transfer to open PSII reaction centers under natural light exposure was $F_{\mathrm{v}}{ }^{\prime} / F_{\mathrm{m}}{ }^{\prime}=$ $\left(F_{\mathrm{m}}{ }^{\prime}-F_{\mathrm{o}}{ }^{\prime}\right) / F_{\mathrm{m}}{ }^{\prime}$. PSII quantum efficiency was calculated as $\Phi$ PSII $=\left(F_{\mathrm{m}}{ }^{\prime}-F_{\mathrm{s}}\right) / F_{\mathrm{m}}{ }^{\prime}$ (Genty et al., 1989).

Two hours before ethylene measurements, plants were moved from the greenhouse to the laboratory and the upper six expanded leaves of each plant were enclosed in clear 1-1 polyurethane bottles. A preliminary test was conducted to confirm that the bottles did not generate detectable ethylene during the experimental period. The stem directly under the sixth expanded leaf was wrapped with a black rubber stopper. The top six leaves were gently placed in the upsidedown bottle before the bottle was sealed with the stopper. Four hours after sealing the bottles, gas samples were analyzed for ethylene using a GC as described in Expt. 1. Two 2-mL samples were taken from each bottle and a mean was calculated.

Expt. 3: Effect of ethylene and water deficit on B. papyrifera. Sixteen paper birch plants of similar size were selected and randomly assigned to each of the following four treatments: 1) well-watered/control (WC); 2) water-stressed (SC); 3) wellwatered + ethylene (WE); and 4) waterstressed + ethylene (SE). Water-deficit treatment was similar as described in Expt. 1. Plants to be treated with ethylene were placed in boxes as described in Expt. 1 and exposed to $1 \mathrm{ppm}(\mathrm{v} / \mathrm{v})$ ethylene for $4 \mathrm{~h}$.

Gas exchange, $\psi_{\text {predawn }}$, chlorophyll fluorescence, and ethylene production measurements were taken at $0,1,2,3,4,5$, and 12 DAT as described in Expt. 2.

Experimental design. All three experiments involved two factors (Expt. 1: irrigation regimes $\times$ ethylene treatments; Expt. 2: irrigation regimes $\times$ ethylene inhibitor treatments; Expt. 3: irrigation regimes $\times$ ethylene treatments) with four replications arranged in a completely randomized design. Data were analyzed using the SAS general linear model procedure (SAS Institute, Cary, NC) with Tukey-Kramer adjustment for multiple comparisons. The percentage of leaf abscission in experiment one was not subjected to arc sine transformation, because the arc sine transformation was developed for binomial proportions and the transformation is unlikely to change the conclusion noticeably unless the proportion ranges from near zero to over $30 \%$ or from below $70 \%$ to $100 \%$ (Snedecor and Cochran, 1989).

\section{Results}

Expt. 1. Before trees were exposed to ethylene, $\psi_{\text {predawn }}$ of well-watered and water-stressed paper birch averaged $\approx-0.5$ $\mathrm{MPa}$ and $-2.5 \mathrm{MPa}$, respectively. Leaf abscission was observed on both wellwatered and water-stressed plants after exposure to $20 \mathrm{ppm}$ ethylene for $72 \mathrm{~h}$ (data not shown). After 96-h exposure, 56\% leaves abscised from well-watered plants and $67 \%$ from water-stressed plants (Table 1). No leaf abscission was observed on control plants not treated with ethylene under well-watered or water-stressed condition after $96 \mathrm{~h}$.

Expt. 2. Well-watered paper birch plants, regardless of ethylene action inhibitor treatments, had $\psi_{\text {predawn }} \approx-0.5 \mathrm{MPa}$. $\psi_{\text {predawn }}$ of all water-stressed plants decreased below $-2.0 \mathrm{MPa}$ at $13 \mathrm{DAT}$.

Inhibitors of ethylene action (1-MCP or STS) did not have a significant effect on gas exchange or chlorophyll fluorescence in well-watered or water-stressed plants, and only water-deficit treatment effect was significant on net photosynthesis, $g_{\mathrm{S}}, F_{\mathrm{v}} / F_{\mathrm{m}}$, $F_{\mathrm{v}}{ }^{\prime} / F_{\mathrm{m}}{ }^{\prime}$, and ФPSII (data not shown).

Ethylene production of water-stressed plants was not significantly different from well-watered plants at $1,2,6,9,13$, and 20 DAT but was higher than well-watered plants at 26 and 35 DAT (Fig. 1). MS had more detectable ethylene production than all other treatments at 35 DAT.

No leaf abscission was observed on wellwatered plants. Therefore, only data on

Table 1. Effect of ethylene treatment and waterdeficit stress on the percentage of total leaf abscised on B. papyrifera. $^{\mathrm{z}}$

\begin{tabular}{lc}
\hline Treatment & $\begin{array}{r}\text { Percentage of total } \\
\text { leaf abscised (\%) }\end{array}$ \\
\hline Well-watered + ethylene & $56(2.4)$ \\
Water-stressed + ethylene & $67(5.5)$ \\
Well-watered + control & $0.0(0.0)$ \\
Water-stressed + control & $0.0(0.0)$ \\
Source & Statistical \\
Ethylene $\times$ water-deficit & significance \\
$\quad$ stress & 0.0539 \\
Ethylene & 0.0001 \\
Water-deficit stress & 0.0539 \\
\hline
\end{tabular}

${ }^{\text {zPlants were enclosed in plastic boxes and exposed }}$ to $20 \mathrm{ppm}(\mathrm{v} / \mathrm{v})$ ethylene for $96 \mathrm{~h}$. Data represents mean (SD); $n=4$. Significance of effect of ethylene treatment and water-deficit stress was presented at the bottom of the table. 


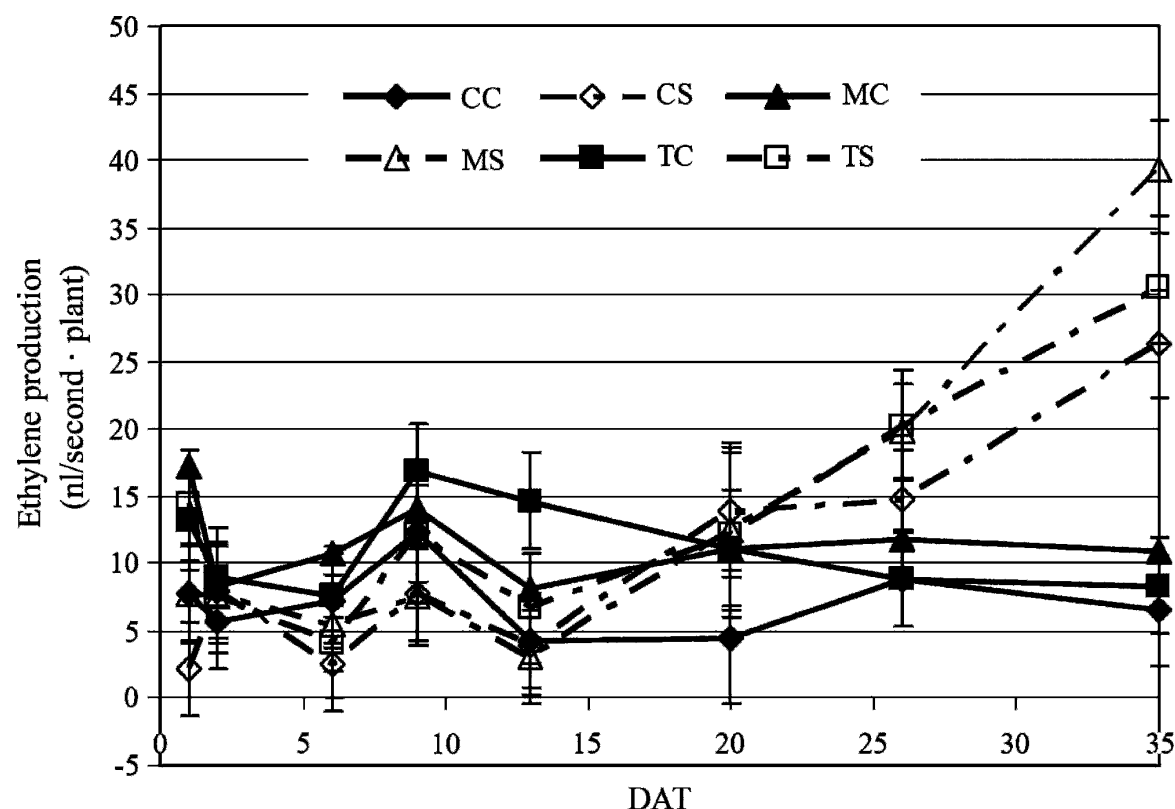

Fig. 1. Ethylene production of $B$. papyrifera at 1, 2, 6, 9, 13, 20, 26, and $35 \mathrm{~d}(\mathrm{~s})$ after treatment (DAT) of different irrigation regimes and ethylene inhibitors. Data points represent mean $\pm \mathrm{SE}$ (Tukey's adjusted; $\mathrm{n}=4) . \mathrm{CC}=$ well-watered; $\mathrm{CS}=$ water-stressed; $\mathrm{MC}=1-\mathrm{MCP}+$ well-watered; $\mathrm{MS}=1-\mathrm{MCP}+$ waterstressed; $\mathrm{TC}=\mathrm{STS}+$ well-watered; TS $=$ STS + water-stressed.

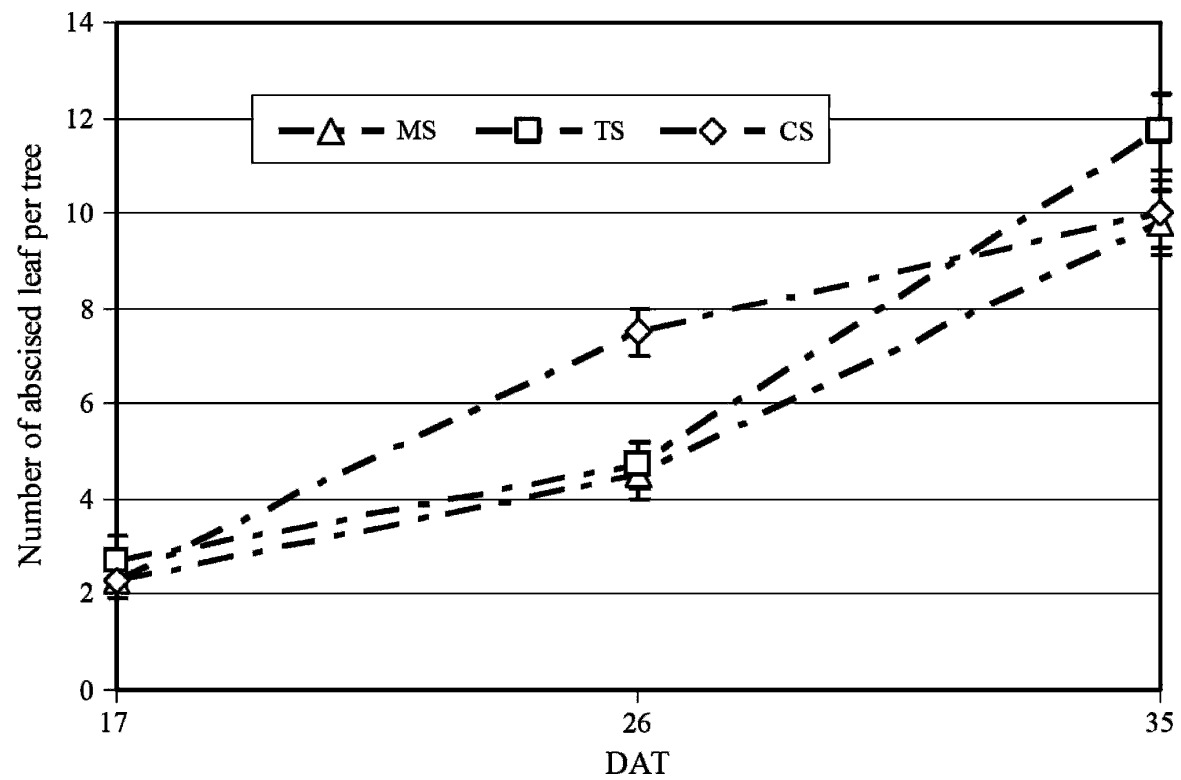

Fig. 2. Number of abscised leaves of B. papyrifera at 17, 26, and $35 \mathrm{~d}(\mathrm{~s})$ after treatment (DAT) of different irrigation regimes and ethylene inhibitors. Data points represent mean \pm SE (Tukey's adjusted; $n=4$ ). MS = 1-MCP + water-stressed; TS = STS + water-stress; CS = water-stressed. All well-watered plants did not abscise leaves $(0 \pm 0)$.

water-stressed plants are presented. Inhibitors of ethylene action did not have a significant effect on leaf abscission at 17 or 35 DAT (Fig. 2). However, more leaf abscission was observed on CS ( 7.5 leaves/tree) than MS plants (4.5 leaves/tree) or TS plants (4.6 leaves/tree) at 26 DAT.

Expt 3. Application of 1 ppm ethylene did not have significant effect on gas exchange or chlorophyll fluorescence in well-watered or water-stressed plants, and only the waterdeficit treatment effect was significant (data not shown). No leaf abscission was observed from well-watered or water-stressed plants during flood stress. In the current study, paper birch abscised more than $50 \%$ of total leaves regardless of plant water status after exposure to a high concentration (20 ppm) of exogenous ethylene for $96 \mathrm{~h}$ (Table 1), which suggests that ethylene may be involved in leaf abscission of paper birch. Application of a physiological level $(1 \mathrm{ppm})$ of ethylene, however, did not cause increased leaf abscission in either well-watered or water-stressed paper birch.

Two different inhibitors of ethylene action were used because one $\left(\mathrm{Ag}^{+}\right)$is thought to irreversibly bind to ethylene binding sites and the other (1-MCP) is thought to have a more transient binding effect unless continuously applied (Cameron and Reid, 2001). 1-MCP and STS delayed leaf abscission at 26 DAT (Fig. 2). Neither 1-MCP nor STS had an effect on plant water status, gas exchange, or chlorophyll fluorescence (data not shown). A significant increase in ethylene production was not detected in water-stressed paper birch before 26 DAT (Fig. 1). A significant increase in endogenous ethylene production was observed in water-stressed paper birch after significant leaf abscission (Fig. 1).

Based on these observations, it would appear that ethylene plays a minor role in water-deficit stress-induced leaf abscission in paper birch, although its effect could not be totally eliminated. Other hormonal factors such as abscisic acid (Fort et al., 1998) or cytokinin (Zhang and Ervin, 2004) might be worth exploring to investigate the effects on leaf abscission on paper birch under water deficit conditions.

\section{Literature Cited}

Arndt, S.K., S.C. Clifford, W. Wanek, H.G. Jones, and M. Popp. 2001. Physiological and morphological adaptations of the fruit tree Ziziphus rotundifolia in response to progressive water deficit stress. Tree Physiol. 21:705-715.

Botondi, R., D. DeSantis, A. Bellincontro, K Vizovitis, and F. Mencarelli. 2003. Influence of ethylene inhibition by 1-methylcyclopropene on apricot quality, volatile production, and glycosidase activity of low- and higharoma varieties of apricots. J. Agr. Food Chem. 51:1189-1200.

Cameron, A.C. and M.S. Reid. 1981. The use of silver thiosulphate anionic complex as a foliar spray. II. Prevention of shattering in potted geraniums. HortScience 16:405. (abstr.).

Cameron, A.C. and M.S. Reid. 2001. 1-MCP blocks ethylene-induced petal abscission of Pelargonium peltatum but the effect is transient. Postharvest Biol. Tech. 22:169-177.

Cheng, L. 2003. Xanthophyll cycle pool size and composition in relation to the nitrogen content of apple leaves. J. Expt. Bot. 54:385-393.

Cinnirella, S., F. Magnani, A. Saracino, and M. Borghetti. 2002. Response of a mature Pinus laricio plantation to a three-year restriction of water supply: Structural and functional acclimation to drought. Tree Physiol. 22:21-30.

Connor, K.F., J.E. Rodgers, and C. Miller. 2005 Parkinsonia L. National Seed Laboratory. USDA Forest Service. 13 Nov. 2005. <http:// www.nsl.fs.fed.us/wpsm/Parkinsonia.pdf $>$.

Cregg, B.M. 2004. Improving drought tolerance of trees: Theoretical and practical considerations. Acta Hort. 630:147-158. 
Fan, X. and J.P. Mattheis. 1999. Impact of 1-methylcyclopropene and methyl jasmonate on apple volatile production. J. Agr. Food Chem. 47:2847-2853.

Farrar, J.L. 1995. Trees of the northern United States and Canada. 1st ed. Iowa State University Press, Ames, IA.

Fort, C., F. Muller, P. Label, A. Granier, and E. Dreyer. 1998. Stomatal conductance, growth and root signaling in Betula pendula seedlings subjected to partial soil drying. Tree Physiol. 18:769-776.

Gomez-Cadena, A., F.R. Tadeo, and M.E. PrimmoMillo. 1996. Leaf abscission induced by ethylene in water-stressed intact seedlings of Cleopatra mandarin requires previous abscisic acid accumulation in roots. Plant Physiol. 112:401408.

Gu, M., J.A. Robbins, and C.R. Rom. 2004. Early field performance of ornamental birch taxa (Betula spp.) at Fayetteville and Hope. Ark. Agr. Exp. Sta. Res. Series 520:41-43.

Gu, M., C.R. Rom, and J.A. Robbins. 2003. Leaf gas exchange and stomatal characteristics of six birch taxa under different irrigation regimes. Ark. Agr. Exp. Sta. Res. Series 506:17-19.

Hall, M.A. and A.R. Smith. 1995. Ethylene and the responses of plants to stress. Bulg. J. Plant Physiol. 21:71-79.

Jiang, Y., D.C. Joyce, and A.J. Macnish. 1999 Response of banana fruits to treatment with 1-methylcyclopropene. Plant Growth Regulat. 28:77-82.

Ladjal, M., D. Epron, and M. Ducrey. 2000. Effect of water deficit preconditioning on thermotolerance of photosystem II and susceptibility of photosynthesis to heat stress in cedar seedlings. Tree Physiol. 20:1235-1241.

Morgan, P.W. and M.C. Drew. 1997. Ethylene and plant responses to stress. Physiol. Plant. 100:620-630.

Morgan, P.W., C. He, J.A. De Greef, and M.P. De Proft. 1990. Does water deficit stress promote ethylene synthesis by intact plants? Plant Physiol. 94:1616-1624.

Muller, R., E.C. Sisler, and M. Serek. 2000. Stress induced ethylene production, ethylene binding, and the response to the ethylene action inhibitor 1-MCP in miniature roses. Sci. Hort. 83:51-59.

Oosterhuis, D.M. and S.D. Wulleschleger. 1987. Osmotic adjustment in cotton (Gossypium hirsutum L.) leaves and roots in response to water stress. Plant Physiol. 84:1154-1157.

Ranney, T.G. and R.E. Bir. 1994. Comparative flood tolerance of birch rootstocks. J. Amer. Soc. Hort. Sci. 119:43-48.

Serek, M., E.C. Sisler, and M.S. Reid. 1994. A volatile ethylene inhibitor improves the postharvest life of potted roses. J. Amer. Soc. Hort. Sci. 119:572-577.

Serek, M., E.C. Sisler, T. Tirosh, and S. Mayak. 1995. 1-methylcyclopropene prevents bud, flower and leaf abscission of Geraldton waxflower. HortScience 30:1310.

Sisler, E.C. and M. Serek. 1997. Inhibitors of ethylene responses in plants at the receptor level: Recent developments. Physiol. Plant. 100:577-582.

Snedecor, G.W. and W.G. Cochran. 1989. Statistical methods. 8th ed. Iowa State University Press, Ames, IA.

Taiz, L. and E. Zeiger. 1998. Plant Physiology. 2nd ed. Sinauer Associates, Inc., Sunderland, MA.

USDA. 2005. USDA NRCS Plant Guide: Paper Birch Betula papyrifera Marsh. 13 Nov. 2005. <http:plants.usda.gov/plantguide/pdf/ pg_bepa.pdf $>$.

van Kooten, O. and J.F.H. Snel. 1990. The use of fluorescence nomenclature in plant stress physiology. Photosyn. Res. 25:147-150.

Wullschleger, S.D. and D.M. Oosterhuis. 1991. Osmotic adjustment and the growth response of seven vegetable crops following water-deficit stress. HortScience 26:1210-1212.

Yin, C., Y. Peng, R. Zang, Y. Zhu, and C. Li. 2005. Adaptive responses of Populus kangdingensis to drought stress. Physiol. Plant. 123:445-451.

Zhang, X. and E.H. Ervin. 2004. Cytokinincontaining seaweed and humic acid extracts associated with creeping bentgrass leaf cytokinins and drought resistance. Crop Sci. 44: 1737-1745. 